\title{
Review
}

\section{Hormone replacement therapy in women with spinal cord injury - a survey with literature review}

\author{
S Khong ${ }^{1}$, G Savic*,2, BP Gardner ${ }^{2}$ and F Ashworth ${ }^{1}$ \\ ${ }^{1}$ Department of Obstetrics and Gynaecology, Stoke Mandeville Hospital, Aylesbury, Bucks, UK; ${ }^{2}$ National Spinal \\ Injuries Centre, Stoke Mandeville Hospital, Aylesbury, Bucks, UK
}

\begin{abstract}
Study design: Postal questionnaire survey.
Objective: To examine the current use of hormone replacement therapy (HRT) in a sample of menopausal women with spinal cord injury (SCI).

Setting: National Spinal Injuries Centre (NSIC), Stoke Mandeville Hospital, Aylesbury, UK. Method: A postal questionnaire was sent to 94 women from the NSIC patient database who met the study inclusion criteria (wheelchair dependent, aged 49 years and above, last seen or heard from within the last 3 years).

Results: A total of 59 valid questionnaires were analysed. At the time of the survey, 50 women were menopausal and 11 of them were using HRT, six for menopausal symptoms and five for osteoporosis prevention. Another 11 had used HRT, eight for menopausal symptoms and three for osteoporosis prevention, but had discontinued it. The main reasons for stopping HRT were side effects. Of the 28 women who had never been on HRT, 20 had either enquired about it, or had been offered HRT, but decided against it. Of the nine women who were still premenopausal at the time of the survey, four would consider using HRT.

Conclusions: Results show that $44 \%$ of the menopausal women in our sample have used HRT at some point and $22 \%$ still do, mostly for treatment of menopausal symptoms and for osteoporosis prevention. In view of the latest literature findings in able-bodied women, use of HRT for osteoporosis prevention in women with SCI may have to be reconsidered.

Sponsorship: Partly supported by the Stoke Mandeville Hospital Charitable Fund.

Spinal Cord (2005) 43, 67-73. doi:10.1038/sj.sc.3101694; Published online 30 November 2004
\end{abstract}

Keywords: spinal cord injury; osteoporosis; menopause; hormone replacement therapy

\section{Introduction}

A woman is deemed to be postmenopausal if her last menstrual period occurred 12 or more months ago. ${ }^{1}$ The menopause is associated with symptoms such as hot flushes, night sweats, sleep disturbances, emotional instability, anxiety, depression, vaginal dryness as well as increased risks of osteoporosis and cardiovascular disease. Hormone replacement therapy (HRT) has been used widely over the past few decades by postmenopausal women in many countries as an effective treatment for menopausal symptoms and urogenital atrophy. HRT has also been shown by several studies to reduce successfully the incidence of osteoporosis ${ }^{2-4}$ and colorectal cancer. $^{2,4,5}$

Observational studies in the past have suggested that both combined oestrogen and progestogen and oestrogen alone HRT preparations reduce the risk of coronary

*Correspondence: G Savic, National Spinal Injuries Centre, Stoke Mandeville Hospital, Aylesbury, Bucks HP21 8AL, UK heart disease $(\mathrm{CHD})^{6-9}$ and cerebrovascular disease $(\mathrm{CVD})^{10-12}$ and are especially effective in secondary prevention in women with established CHD or CVD. However, more recent randomised controlled trials have disproved earlier beliefs and have failed to show these benefits. $^{2,13-16}$ They demonstrated that HRT does not offer any cardiovascular ${ }^{13-15}$ or cerebrovascular ${ }^{16}$ pro- $^{1}$ tection, but instead increases the risks of the ischaemic heart disease $\mathrm{e}^{2,17}$ and stroke. ${ }^{2,18}$ The same studies simultaneously confirmed the two well-known side effects of HRT: increased risk of breast cancer, ${ }^{2,19-22}$ which rises with the duration of $\mathrm{HRT}^{19}$ and is substantially greater in oestrogen-progestogen combined HRT; ${ }^{20}$ and increased risk of thromboembolism, ${ }^{2,13,23,24}$ which seems to be highest in the first year of use. ${ }^{24}$ Other reported side effects were increased risk of gall bladder diseases, ${ }^{13}$ increased risk of ovarian cancer with continuous use of combined $\mathrm{HRT}^{25}$ and increased risk of dementia in women aged 65 and 
older. $^{26}$ These new findings have caused much uncertainty among women and their doctors regarding the usage of HRT.

The risk-benefit ratio is even more complex in a woman with spinal cord injury (SCI). Immobilisation after SCI is associated with marked increase in bone resorption and only minor changes in bone formation, which result in loss of bone mineral density and osteoporosis in those parts of the skeleton that are no longer weight bearing. ${ }^{27-29}$ The only exception is the lumbar spine, where bone mineral density is preserved or even increased with time since injury. ${ }^{29-31}$ Studies have shown that the major sublesional bone loss occurs during the first 2 years after injury and at a slower rate thereafter, ${ }^{30-32}$ with bone mineral density reaching fracture threshold between 1 and 5 years after injury. ${ }^{32,33}$ The loss of sensation and proprioception further increases the risk of pathological bone fractures, which adds to the morbidity, hospital readmissions and cost of treatment in patients with chronic SCI. ${ }^{34-36} \mathrm{HRT}$ could reduce the risk of fracture by slowing the further development of osteoporosis following menopause, ${ }^{37}$ but no longitudinal studies have been carried out in women with SCI to confirm this. Other potential benefits of HRT in women with SCI could be in treating atrophic vaginitis and reducing the incidence of urinary tract infections, especially in women on indwelling or intermittent catheterisation, and in lowering the incidence of colorectal cancer. Conversely, being on HRT could further increase the thromboembolic risk, but there have been no studies to date that have assessed the additional risk of thromboembolism due to long-term immobility in women with SCI.

Risks and benefits of HRT are summarised in Table 1.

There is very little information in the medical literature about the use of HRT by women with SCI. ${ }^{38,39}$ We found only one publication in the English literature, a multicentre study of self-reported reproductive health after SCI, which mentions the percentages of women on HRT, but not the main reasons for treatment or its duration. ${ }^{40}$

We conducted a postal survey at the National Spinal Injuries Centre (NSIC), Stoke Mandeville Hospital to establish the uptake of HRT by women with longstanding SCI in our centre.

\section{Materials and methods}

The NSIC active patient database (database of patients who contacted or attended the Centre in the last 3 years) was searched for female patients aged 49 years and older who were regular wheelchair users (ASIA/Frankel grade A, B or C) ${ }^{41,42}$ The 94 women who met the study inclusion criteria were sent a 20 -item postal questionnaire about current and previous HRT use, brief gynaecological history and basic demographic information.

Table 1 Risks and benefits of hormone replacement therapy

\section{Risks}

Increased risk of

Breast cancer

Thromboembolism

Cerebrovascular disease

Coronary heart disease

Reduced risk of

Osteoporosis

Colorectal cancer
Absolute excess risk per 10000 person-years

Eight extra invasive breast cancers ${ }^{\mathrm{a}}$

Eight extra pulmonary emboli ${ }^{\mathrm{a}}$

Eight extra strokes ${ }^{a}$

Seven extra coronary heart diseases ${ }^{a}$

\section{Benefits}

Absolute risk reduction per 10000 person-years

Five fewer hip fractures ${ }^{\mathrm{a}, \mathrm{b}}$

Six fewer colorectal cancers ${ }^{\mathrm{a}}$

Risk-benefit balance

Absolute excess risk 19 events per 10000 person-years ${ }^{\mathrm{a}}$

Established treatment for

Condition

Menopausal symptoms

Urogenital atrophy ${ }^{b}$

${ }^{a}$ Results from The Women's Health Initiative Study ${ }^{2}$

${ }^{b}$ Possible additional benefit in postmenopausal women with spinal cord injury

\section{Results}

A total of 61 questionnaires were returned (response rate $65 \%$ ). Two of these were excluded from the analysis, because the patients were functional walkers. In all, 59 valid questionnaires were analysed (effective response rate $62 \%$ ).

\section{Sample characteristics}

All 59 patients were regular wheelchair users, 22 were tetraplegic and 37 paraplegic, 31 had a complete injury (ASIA/Frankel grade A) and 28 incomplete (ASIA/ Frankel grade $\mathrm{B}$ or $\mathrm{C}$ ). The mean age of the sample was 59 years, with the age range $49-72$ years, mean age at injury was 28 years (range $0-53$ ) and mean time since injury was 31 years (range 9-59). At the time of the survey, 50 women were menopausal, with the mean age of 60 years and range 50-72 years. Nine women were premenopausal, with the mean age of 52 years and range $49-55$ years.

\section{HRT use}

The summary of HRT use is given in Table 2 .

Of the 50 menopausal women, $11(22 \%)$ were on HRT at the time of the survey and another $11(22 \%)$ had been on HRT in the past, but had discontinued the treatment before the survey. The main reasons for starting HRT were menopausal symptoms in 14 women $(28 \%)$ and osteoporosis prevention in eight women $(16 \%)$. The mean age when HRT was started was 48.8 years (range 38-56). Mean duration of treatment was 10.6 years in the 11 women still on HRT (range 6-15) 
Table 2 HRT use in the 50 menopausal women with spinal cord injury

\begin{tabular}{lccc}
\hline & \multicolumn{4}{c}{ HRT use } \\
\cline { 2 - 3 } & Ever on HRT 22(44\%) & Never on HRT \\
& $28(56 \%)$ \\
\cline { 2 - 3 } & $\begin{array}{c}\text { Current users } \\
11(22 \%)\end{array}$ & $\begin{array}{c}\text { Past users } \\
11(22 \%)\end{array}$ & - \\
\hline $\begin{array}{c}\text { Indications } \\
\text { Menopausal } \\
\text { symptoms }\end{array}$ & \multicolumn{4}{c}{$14(28 \%)$} & - \\
$\begin{array}{l}\text { Osteoporosis } \\
\text { prevention }\end{array}$ & $5(12 \%)$ & $8(16 \%)$ & - \\
\hline
\end{tabular}

HRT: hormone replacement therapy

and 7.2 years in the 11 women no longer on HRT (range $0.5-15$ ). In the 11 women still on HRT, the main reasons for starting HRT were menopausal symptoms in six $(12 \%)$ and osteoporosis prevention in five $(10 \%)$. Of the 11 women who had discontinued HRT, eight $(16 \%)$ had been on it for menopausal symptoms and three $(6 \%)$ for osteoporosis prevention. The main reasons for stopping HRT in these women were side effects in four cases, lack of desired effect on menopausal symptoms in three cases, unspecified personal choice in two cases and newly diagnosed breast cancer in two women.

Of the 28 menopausal women $(56 \%)$ who had never been on HRT, 20 had either enquired about it or had been offered HRT, but decided against it. Of the nine women who were still premenopausal at the time of the survey, four would consider using HRT.

The majority of women in our sample were started on HRT or had discussed it with their general practitioners. Only five had discussed it with their spinal consultant and/or a gynaecologist.

\section{Other medication}

Other medications taken for osteoporosis prevention were biphosphonates by five women, of whom three were on HRT at the same time, and calcium supplements by 14 women, of whom four were on HRT as well.

\section{Discussion}

The results of our study show that $22 \%$ of menopausal women in our sample were on HRT at the time of the survey. This percentage of current HRT users is somewhat higher than the $20 \%$ reported in 1999 in the general population in Great Britain, ${ }^{43}$ but much lower than the estimated $41 \%$ of current users in a general population sample in the USA in $1997 .{ }^{44}$ The combined number of current and past users in our sample (44\%) is higher than in the USA sample of SCI women $(35 \%$ preinjury and $26 \%$ postinjury), ${ }^{40}$ but lower than the $60 \%$ reported in a 2002 British community survey of women aged 51-57 years. ${ }^{45}$ The average duration of treatment in our sample was more than twice as long as in the general population, probably because almost half of the women on HRT in our study were taking it for osteoporosis prevention. Another interesting finding was that a much higher percentage of women in our sample have considered or at least discussed HRT use with their doctors as compared with the general population in Great Britain, ${ }^{43}$ probably due to the potential additional benefits of HRT in relation to osteoporosis after SCI. It is worth noting that the data collection for this study took place before the latest results of the Women's Health Initiative ${ }^{2}$ and Million Women Study ${ }^{20}$ were published. The proportion of women who decide to start or continue HRT may have changed since then, both in the general population ${ }^{44,46}$ and in women with SCI.

It remains a difficult decision for women with SCI and their doctors to decide whether to use HRT for menopause symptom control and what treatment they should adopt to reduce the risk of osteoporosis and future bone fractures. Evidence from large randomised controlled studies, especially the Heart and Estrogen/ progestin Replacement Study (HERS) ${ }^{13,14}$ and the Women's Health Initiative (WHI) Study, 2,25,26 demonstrating increased incidence of CHD, CVD, breast cancer, thromboembolism, gall bladder diseases, ovarian cancer and dementia associated with the use of HRT, has made decision making even more complex. A number of factors need to be taken into consideration in making the final decision: concurrent problems affecting quality of life, such as vasomotor, psychological and other menopausal symptoms, the absolute risk of fracture based on the individual's risk assessment, clinical findings, personal and family history as well as the duration and cost of potential treatment. ${ }^{47-51}$

The majority of patients in our sample were on HRT for menopausal symptom control - about two-thirds of all users and just over half of current users. There is very little information in the medical literature about the menopause in women with SCI, ${ }^{39,40}$ but the few studies we found suggest that some menopausal symptoms may be worse after SCI. HRT is well established and widely accepted as the only effective treatment for menopausal symptoms in the general population and there is no reason why the same would not apply to women with SCI.

A third of our responders who were or had been on HRT and almost half of the current HRT users were taking it for osteoporosis prevention. The mean duration of treatment in this subgroup was longer than in the subgroup taking HRT for menopausal symptoms. Most studies looking at the effectiveness of HRT in osteoporosis prevention have been carried out on postmenopausal ambulatory women. ${ }^{52-54}$ No published studies, to our knowledge, have included women with SCI. As the bone mineral density in women with SCI is already reduced due to their paralysis, ${ }^{31,37}$ additional bone loss 
after menopause could put them at higher fracture risk. There have been reports on higher fracture incidence with increasing age and time postinjury, especially in women, ${ }^{40,55}$ but the additional postmenopausal risk has not been quantified. ${ }^{38}$

It is our personal experience that patients often ask clinicians' opinion on HRT and osteoporosis. To identify the specific risks and benefits for a woman with SCI, studies would specifically have to recruit peri- and postmenopausal women with SCI. Such trials would be difficult to set-up. With only approximately $20 \%$ of the traumatic SCI population being women, ${ }^{56,57}$ recruitment would take a long time. Follow-up would need to be of a sufficient length to analyse adequately the risks and benefits for women with SCI. The sample population would be heterogeneous, as the subjects would have had different bone densities prior to sustaining their SCI, as well as spinal cord lesions located at different levels and of varying severity. The management and treatment of the patients at various medical centres are different. All these confounding factors would need to be taken into account when setting up a study. Patient recruitment would be even more difficult now, in view of the latest randomised controlled trial results in ablebodied women. Two big HRT trials, the $\mathrm{WHI}^{2}$ and the HABITS ${ }^{22}$ had to be stopped prematurely because they exceeded the stopping boundary for adverse effects and the global index statistics showed that risks exceeded benefits. For the same reason, early in March this year the oestrogen arm of the $\mathrm{WHI}^{58}$ was stopped prematurely and the participants were asked to start the follow-up phase. It is very unlikely that a randomised controlled trial in women with SCI could be carried out and the decision to commence or continue HRT would need to be in each individual case after a risk assessment. The current recommendations by the British Committee on Safety of Medicines (CSM) ${ }^{59}$ and the American Food and Drug Administration (FDA) ${ }^{60}$ are that HRT be used for short-duration treatment of moderate and severe menopausal symptoms and not as a first-line prevention of osteoporosis.

HRT is currently the only effective treatment for menopausal symptoms. However, there are other drugs for postmenopausal osteoporosis prevention and treatment. ${ }^{61-65}$ Calcium supplements and vitamin $D$, calcitonin, thiazide diuretics, selective oestrogen receptor modulators (SERMs), biphosponates and recombinant human parathyroid hormone have been shown to reduce osteoporosis in postmenopausal women, but they have not been studied in women with SCI. Most antiresorptive drugs can reduce the risk of osteoporotic vertebral fractures, but only few have been proven to reduce the risk of nonvertebral fractures as well, which would be needed for the SCI population. Bisphosphonates, such as alendronate, risedronate, etidronate and tiludronate, reduce osteoclast-mediated resorption and bone remodelling and can reduce the relative risks of both vertebral and nonvertebral fractures. ${ }^{66,67}$ They are the only medications for which we found some published reports of use in people with SCI, with possibly promising results. ${ }^{68-70}$ Thiazide diuretics were shown to slow down cortical bone loss in healthy postmenopausal women ${ }^{71}$ and in healthy older adults ${ }^{72}$ but with modest effects overall, ${ }^{71,72}$ somewhat stronger in women. ${ }^{72} \mathrm{~A}$ new bone formation enhancing drug, recombinant human parathyroid hormone, which has recently been approved in the USA and Europe, has been shown to increase bone mass and reduce incidence of both vertebral and nonvertebral fractures. ${ }^{73-75}$ In an effort to achieve stronger therapeutic effects, combination treatments for osteoporosis are beginning to be explored, and while it seems that combinations of some antiresorptive treatments may have synergistic effect, ${ }^{76}$ optimal ways of combining them with bone formation stimulating drugs without reducing the anabolic effect of the latter are yet to be found. ${ }^{77}$ Studies in able-bodied postmenopausal women show that exercise may be an effective nonpharmacological way of slowing the rate of bone loss. ${ }^{78}$ Exercise has been widely used in people with SCI for its many benefits, but with somewhat disappointing results in osteoporosis prevention. Studies in patients with SCI showed physical therapy, including standing, walking, weight-bearing exercise and functional electrical stimulation, to be either ineffective in preventing bone loss below the level of injury ${ }^{7-83}$ or partly effective and only with regular and sufficient use, ${ }^{84,85}$ which is rarely feasible in everyday life.

As with HRT, none of the above drugs are without their side effects, and the final decision on which treatment is best for a particular patient will depend on a detailed risk-benefit assessment in each individual case.

\section{Conclusions}

At the time of the survey, $22 \%$ of menopausal women in our sample were on HRT and another $22 \%$ had been on HRT at some point, but had discontinued its use. The main indications for starting HRT were menopausal symptoms and osteoporosis prevention. In the light of the recent published work on HRT in able-bodied women, it would seem appropriate to recommend HRT for short-term relief of menopausal symptoms, but to consider alternative managements for osteoporosis prevention in women with SCI.

\section{Acknowledgements}

The study was partly supported by the Stoke Mandeville Hospital Charitable Fund. The authors wish to thank the participants for taking part in the survey.

\section{References}

1 Cochrane HRT Study Group. Hormone replacement therapy for perimenopausal and postmenopausal women (Protocol for a Cochrane Review). In: The Cochrane Library, Issue 1. John Wiley \& Sons, Ltd.: Chichester, UK 2004. 
2 Rossouw JE, et al,, Writing Group for the Women's Health Initiative Investigators. Risks and benefits of estrogen plus progestin in healthy postmenopausal women: principal results from the Women's Health Initiative randomised controlled trial. JAMA 2002; 288: 321-333.

3 Weiss NS, Ure CL, Ballard JH, Williams AR, Daling JR. Decreased risk of fractures of the hip and lower forearm with postmenopausal use of estrogen. N Engl J Med 1980; 303: $1195-1198$.

4 Nelson HD, Humphrey LL, Nygren P, Teutsch SM, Allan JD. Postmenopausal hormone replacement therapy: scientific review. JAMA 2002; 288: 872-881.

5 Grodstein F, Newcomb PA, Stampfer MJ. Postmenopausal hormone replacement therapy and the risk of colorectal cancer: a review and meta-analysis. Am J Med 1999; 106: 574-582.

6 Henderson BE, Paganini-Hill A, Ross RK. Estrogen replacements therapy and protection from acute myocardial infarction. Am J Obstet Gynecol 1988; 159: 312-317.

7 Hunt K, Vessey M, McPherson K. Mortality in a cohort of long-term users of hormone replacement therapy: an updated analysis. $\mathrm{Br} \quad J$ Obstet Gynaecol 1990; 97: 1080-1086.

8 Weiss NS. Health consequences of short- and long-term postmenopausal hormone therapy. Clin Chem 1996; 42(8 Part 2): 1342-1344.

9 Grodstein F, Stampfer MJ, Falkeborn M, Naessen T, Persson I. Postmenopausal hormone therapy and risk of cardiovascular disease and hip fracture in a cohort of Swedish women. Epidemiology 1999; 10: 476-480.

10 Paganini-Hill A, Ross RK, Henderson BE. Postmenopausal oestrogen treatment and stroke: a prospective study. BMJ 1988; 297: 519-522.

11 Finucane FF, Madans JH, Bush TL, Wolf PH, Kleinman JC. Decreased risk of stroke among postmenopausal hormone users: results from a national cohort. Arch Intern Med 1993; 153: 73-79.

12 Falkeborn M, Persson L, Terent A, Adami HO, Lithell H, Bergstrom R. Hormone replacement therapy and the risk of stroke: follow-up of a population-based cohort in Sweden. Arch Intern Med 1993; 153: 1201-1209.

13 Hulley S et al. Randomized trial of estrogen plus progestin for secondary prevention of coronary heart disease in postmenopausal women. Heart and Estrogen/progestin Replacement Study (HERS) Research Group. JAMA 1998; 280: 605-613.

14 Grady D, et al, HERS Research Group. Cardiovascular disease outcomes during 6.8 years of hormone therapy: Heart and Estrogen/progestin Replacement Study followup (HERS II). JAMA 2002; 288: 49-57.

15 Hippisley-Cox J, Pringle M, Crown N, Coupland C. A case-control study on the effect of hormone replacement therapy on ischaemic heart disease. Br J Gen Pract 2003; 53: 191-196.

16 Viscoli CM, Brass LM, Kernan WN, Sarrel PM, Suissa S, Horwitz RI. A clinical trial of estrogen-replacement therapy after ischemic stroke. $N$ Engl J Med 2001; 345: 1243-1249.

17 Menson JE, et al, Women's Health Initiative Investigators. Estrogen plus progestin and the risk of coronary heart desease. N Engl J Med 2003; 349: 523-534.

18 Wassertheil-Smoller S, et al,, WHI Investigators. Effects of estrogen plus progestin on stroke in postmenopausal women: the Women's Health Initiative: a randomized trial. JAMA 2003; 289: 2673-2684.
19 Collaborative Group on Hormonal Factors in Breast Cancer. Breast cancer and hormone replacement therapy: collaborative reanalysis of data from 51 epidemiological studies of 52705 women with breast cancer and 108411 women without breast cancer. Lancet 1997; 350: 1047-1059.

20 Beral V, Million Women Study Collaborators. Breast cancer and hormone-replacement therapy in the Million Women Study. Lancet 2003; 362: 419-427.

21 Chlebowski RT, et al,, WHI Investigators. Influence of estrogen plus progestin on breast cancer and mammography in healthy postmenopausal women: the Women's Health Initiative Randomized Trial. JAMA 2003; 289: 3243-3253.

22 Holmberg L, Anderson H, HABITS steering and data monitoring committees. HABITS (hormonal replacement therapy after breast cancer-is it safe?), a randomised comparison: trial stopped. Lancet 2004; 363: 453-455.

23 Hoibraaten E, Qvigstad E, Arnesen H, Larsen S, Wickstrom E, Sandset PM. Increased risk of recurrent venous thromboembolism during hormone replacement therapy: results of the randomized, double-blind, placebo-controlled estrogen in venous thromboembolism trial (EVTET). Thromb Haemost 2000; 84: 961-967.

24 Miller J, Chan BKS, Nelson HD. Postmenopausal estrogen replacement and risk for venous thromboembolism: a systematic review and meta-analysis for the US Preventative Services Task Force. Ann Intern Med 2002; 136: 680-690.

25 Anderson GL, et al,, Women's Health Initiative Investigators. Effects of estrogen plus progestin on gynecological cancers and associated diagnostic procedures: the Women's Health Initiative randomized trial. JAMA 2003; 290: 1739-1748.

26 Shumaker SA, et al,, WHIMS Investigators. Estrogen plus progestin and the incidence of dementia and mild cognitive impairment in postmenopausal women: the Women's Health Initiative Memory Study: a randomized controlled trial. JAMA 2003; 289: 2651-2662.

27 Roberts D et al. Longitudinal study of bone turnover after acute spinal cord injury. J Clin Endorcinol Metab 1998; 83: 415-422.

28 Takata S, Yasui N. Disuse osteoporosis. J Med Invest 2001; 48: 147-156.

29 Biering-Sorensen F, Bohr H, Schaadt O. Bone mineral content of the lumbar spine and lower extremities years after spinal cord lesion. Paraplegia 1988; 26: 293-301.

30 Biering-Sorensen F, Bohr HH, Schaadt OP. Longitudinal study of bone mineral content in the lumbar spine, the forearm and the lower extremities after spinal cord injury. Eur J Clin Invest 1990; 20: 330-335.

31 Garland DE, Adkins RH, Stewart CA, Ashford R, Vigil D. Regional osteoporosis in women who have a complete spinal cord injury. J Bone Joint Surg Am 2001; 83-A: 1195-1200.

32 Garland DE et al. Osteoporosis after spinal cord injury. J Orthop Res 1992; 10: 371-378.

33 Szollar SM, Martin EM, Sartoris DJ, Parthemore JG, Deftos LJ. Bone mineral density and indexes of bone metabolism in spinal cord injury. Am J Phys Med Rehab 1998; 77: 28-35.

34 Ragnarsson KT, Sell GH. Lower extremity fractures after spinal cord injury: a retrospective study. Arch Phys Med Rehab 1981; 62: 418-423.

35 Nelson A, Ahmed S, Harrow J, Fitzgerald S, SanchezAnguiano A, Gavin-Dreschnack D. Fall-related fractures in persons with spinal cord impairment: a descriptive analysis. SCI Nurs 2003; 20: 30-37. 
36 Savic G, Short DJ, Weitzenkamp D, Charlifue S, Gardner BP. Hospital readmissions in people with chronic spinal cord injury. Spinal Cord 2000; 38: 371-377.

37 Ott SM. Osteoporosis in women with spinal cord injuries. Phys Med Rehab Clin N Am 2001; 12: 111-131.

38 Weeks C. Women, spinal cord injury and osteoporosis. Top Spinal Cord Injury Rehab 2001; 7: 53-63.

39 Jackson AB. Menopausal issues after spinal cord injury. Top Spinal Cord Injury Rehab 2001; 7: 64-71.

40 Jackson AB, Wadley V. A multicenter study of women's self-reported reproductive health after spinal cord injury. Arch Phys Med Rehab 1999; 80: 1420-1428.

41 Maynard Jr FM et al. International standards for neurological and functional classification of spinal cord injury. Spinal Cord 1997; 35: 266-274.

42 Frankel HL et al. The value of postural reduction in the initial management of closed injuries of the spine with paraplegia and tetraplegia. Paraplegia 1969; 7: 179-192.

43 Hope S. Key developments in women's health. Practitioner 1999; 243: 455-456, 459-461.

44 Haas JS, Kaplan CP, Gerstenberger EP, Kerlikowske K. Changes in the use of postmenopausal hormone therapy after the publication of clinical trial results. Ann Intern Med 2004; 140: 184-188.

45 Ballard K. Women's use of hormone replacement therapy for disease prevention: results of a community survey. $\mathrm{Br} J$ Gen Pract 2002; 52: 835-857.

46 Hersh AL, Stefanick ML, Stafford RS. National use of postmenopausal hormone therapy: annual trends and response to recent evidence. JAMA 2004; 291: 47-53.

47 Minelli C, Abrams KR, Sutton AJ, Cooper NJ. Benefits and harms associated with hormone replacement therapy: clinical decision analysis. BMJ 2004; 328: 371.

48 Kim C, Kwok YS. Decision analysis of hormone replacement therapy after the Women's Health Initiative. $A m J$ Obstet Gynecol 2003; 189: 1228-1233.

49 Brennan K, Ayres J. The pros and cons of hormone replacement therapy. Nurs Times 2003; 99: 26-27.

50 Hays $\mathbf{J}$, et al,, Women's Health Initiative Investigators. Effects of estrogen plus progestin on health-related quality of life. N Engl J Med 2003; 348: 1839-1854.

51 Mullins CD, Ohsfeldt RL. Modeling of annual costs of postmenopausal prevention therapy: raloxifene, alendronate or estrogen-progestin therapy. J Manag Care Pharm 2003; 9: 150-158.

52 Torgerson DJ, Bell-Syer SE. Hormone replacement therapy and prevention of vertebral fractures: a metaanalysis of randomised trails. MBC Musculoskelet Disord 2001; 2: 7.

53 Barrett-Connor E et al. Recency and duration of postmenopausal hormone therapy: effects on bone mineral density and fracture risk in the National Osteoporosis Risk Assessment (NORA) study. Menopause 2003; 10: 412-419.

54 Cauley JA, et al,, Women's Health Initiative Investigators. Effects of estrogen plus progestin on risk of fracture and bone mineral density: the Women's Health Initiative randomized trial. JAMA 2003; 290: 1729-1738.

55 Vestergaard P, Krogh K, Rejnmark L, Mosekilde L. Fracture rates and risk factors for fractures in patients with spinal cord injury. Spinal Cord 1998; 36: 790-796.

56 Stover SL, DeLisa JA, Whiteneck GG (eds). Spinal Cord Injury: Clinical Outcomes from the Model Systems. Aspen: Gaithensburg, MD 1995.

57 Frankel HL et al. Long-term survival in spinal cord injury: a fifty year investigation. Spinal Cord 1998; 36: 266-274.
58 Clinical Alert: NIH asks participants in Women's Health Initiative estrogen-alone study to stop study pills, begin follow-up phase, [online] 2004 [cited 02 March 2004]. Available from: URL:. http://www.nlm.nih.gov/databases/ alerts/estrogen_alone.html.

59 Duff G. Further advice on safety of HRT: risk-benefit unfavourable for first-line use in prevention of osteoporosis, [online] 2003 [cited 03 December 2003]. Available from: URL:. http://medicines.mhra.gov.uk.

60 Deady J. Clinical monograph: hormone replacement therapy. J Manag Care Pharm 2004; 10: 33-47.

61 Shoemaker JR, Klemes AB. Alternate options to hormone replacement therapy for osteoporosis. J Am Osteopathol Assoc 2003; 103(10 Suppl 6): S1-S5.

62 Ettinger MP. Aging bone and osteoporosis: strategies for preventing fractures in the elderly. Arch Intern Med 2003; 163: $2237-2246$.

63 Reid IR. Pharmacotherapy of osteoporosis in postmenopausal women: focus on safety. Fxpert Opin Drug Safety 2002; 1: 93-107.

64 Martens MG. Risk of fracture and treatment to prevent osteoporosis-related fracture in postmenopausal women: a review. J Reprod Med 2003; 48: 425-434.

65 Wei GS, Jackson JL, Hatzigeorgiou C, Tofferi JK. Osteoporosis management in the new millennium. Prim Care 2003; 30: 711-741, vi-vii.

66 Watts NB. Bisphosphonate treatment of osteoporosis. Clin Geriatr 2003; 19: 395-414.

67 Fleisch H. Bisphosphonates in osteoporosis. Eur Spine 2003; 12(Suppl 2): S142-S146.

68 Chappard D et al. Effects of tiludronate on bone loss in paraplegic patients. J Bone Miner Res 1995; 10: 112-118.

69 Pearson EG, Nance PW, Leslie WD, Ludwig S. Cyclical etidronate: its effect on bone density in patients with acute spinal cord injury. Arch Phys Med Rehab 1997; 78: 269-272.

70 Sniger W, Garshick E. Alendronate increases bone density in chronic spinal cord injury: a case report. Arch Phys Med Rehab 2002; 83: 139-140.

71 Reid IR et al. Hydrochlorothiazide reduces loss of cortical bone in normal postmenopausal women: a randomised controlled trial. Am J Med 2000; 109: 362-370.

72 LaCroix AZ, Ott SM, Ichikawa L, Scholes D, Barlow WE. Low-dose hydrochlorothiazide and preservation of bone mineral density in older adults: a randomized, doubleblind, placebo-controlled trial. Ann Intern Med 2000; 133: 516-526.

73 Hodsman AB et al. Efficacy and safety of human parathyroid hormone - (1-84) in increasing bone mineral density in postmenopausal osteoporosis. J Clin Endocrinol Metab 2003; 88: 5212-5220.

74 Debiais F. Efficacy data on teriparatide (parathyroid hormone) in patients with postmenopausal osteoporosis. Joint Bone Spine 2003; 70: 465-470.

75 Deal C. The use of intermittent human parathyroid hormone as a treatment for osteoporosis. Curr Rheumatol Rep 2004; 6: 49-58.

76 Simon JA, Mack CJ. Treatment of osteoporosis: combination therapies. Int J Fertil Womens Med 2003; 48: 127-131; discussion 137-138.

77 Black DM et al. PaTH Study Investigators. The effects of parathyroid hormone and alendronate alone or in combination in postmenopausal osteoporosis. $N$ Engl $\mathrm{J} \mathrm{Med}$ 2003; 349: 1207-1215. 
78 Kelley GA. Exercise and regional bone mineral density in postmenopausal women: a meta-analysis review of randomized trials. Am J Phys Med Rehab 1998; 77: 76-87.

79 Dauty M, Perrouin VB, Maugars Y, Dubois C, Mathe JF. Supralesional and sublesional bone mineral density in spinal cord-injured patients. Bone 2000; 27: 305-309.

80 Needham-Shropshire BM, Broton JG, Klose KJ, Lebwohl N, Guest RS, Jacobs PL. Evaluation of a training program for persons with SCI paraplegia using the Parastep 1 ambulation system: part 3. Lack of effect on bone mineral density. Arch Phys Med Rehab 1997; 78: 799-803.

81 BeDell KK, Scremin AM, Perell KL, Kunkel CF. Effects of functional electrical stimulation-induced lower extremity cycling on bone density of spinal cord-injured patients. Am J Phys Med Rehab 1996; 75: 29-34.
82 Eser P, de Bruin ED, Telley I, Lechner HE, Knecht H, Stussi E. Effects of electrical stimulation-induced cycling on bone mineral density in spinal cord-injured patients. Eur $J$ Clin Invest 2003; 33: 412-419.

83 Jones LM, Legge M, Goulding A. Intensive exercise may preserve bone mass of the upper limbs in spinal cord injured males but does not retard demineralisation of the lower body. Spinal Cord 2002; 40: 230-235.

84 Mohr T, Podenphant J, Biering-Sorensen F, Galbo H, Thamsborg G, Kjaer M. Increased bone mineral density after prolonged electrically induced cycle training of paralysed limbs in spinal cord injured man. Calcif Tissue Int 1997; 61: 22-25.

85 Belanger M, Stein RB, Wheeler GD, Gordon T, Leduc B. Electrical stimulation: can it increase muscle strength and reverse osteopenia in spinal cord injured individuals? Arch Phys Med Rehab 2000; 81: 1090-1098. 